\title{
Factors Affecting Employee Retention At The University Of Eldoret, Kenya
}

\author{
Ednah Jepkemboi Rono ${ }^{1}$, Dr Geoffrey Kimutai Kiptum², \\ ${ }^{1}$ Masters Student, School Of Human Resource Management, Jomo Kenyatta University Of Science And \\ Technology, Kenya \\ ${ }^{2}$ Lecturer, School Of Human Resource Management, Jomo Kenyatta University Of Science And Technology, \\ Kenya
}

\begin{abstract}
Many organizations do not consider the factors determining employee retention as a strategy in managing competition and are likely to become victims of industry competition. The purpose of the study was to find out the factors affecting employee retention in an organization in University of Eldoret. Specific objectives were to determine effects of compensation on employee retention. The study will be guided by Maslow'sHierarchy of needs theory, Equity theory and Herzberg's theory; the study adopted a descriptive research design. The research was carried out in University of Eldoret which is in Uasin Gishu County. The target population for this study was 1500 respondents drawn from different levels of management in University of Eldoret. The researchers used purposive sampling method to sample top and middle level managers. Simple random method was used to determine sample size of other employees. Questionnaires will be used as data collection instruments. In this study, the validity of the instruments was tested through pilot testing conducted prior to the study and reliability was tested through test-retest technique by use of Cronbachs' Alpha. The data was analyzed using Chi square and presented in tables. The study findings indicated that compensation, had significant relationship with employee retention. Based on the findings of this study, the following recommendations were made: University of Eldoret should ensure that the policy governing the level of compensation should be improved to enhance a higher rate of employee retention; they should ensure availability of comprehensive range of training, skill and career development which is a key factor of employee attraction and retention, a training program should be established as a regular practice for provision of training and retraining especially refreshment courses opportunities for their employees. This would not only satisfy employees' growth need but also enhance employee retention. lastly, the study suggested that there is a need for further research geared toward establishing the factors affecting employee retention in other industries like banking sector, manufacturing industries, as well as other educational institutions so that the area of study is equipped with more information and allow for generalization of results.
\end{abstract}

Keywords: Compensation and Employee retention

\section{Introduction}

The retention of employees has been shown to be significant to the development and the accomplishment of organization's goals and objectives especially in building competitive advantage over other organization in the phase of increased globalization. Today, changes in technology, global economics, trade agreements, and the like are directly affecting employee/employer relationships thus leading to high employee turnovers thereby affecting employee retention in an organization. According to Coff, (1996), outstanding employees may leave an organization because they became dissatisfied, under paid or unmotivated and while trying to retain employees within the organization they may present other challenges as well. Cappelli (2000) indicates that several factors are considered important in a well-functioning of employee retention. The determinants that are considered to have a direct effect on employee retention include: career opportunities, work environment and work-life balance. Cole (2000) suggests that people stay at such companies where there is a sense of pride and will work to their fullest potential. The reasons to stay are work environment, rewards, growth and development and work-life balance.

The review of the current study unanimously acknowledges that successful organizations share a fundamental philosophy of valuing and investing in their employees(Maguire, 1995; Annand, 1997) and managing retention of promising employees is considered as fundamental of mean of achieving competitive advantage amongst organization (walker, 2001). Aliya and Fariduddin (2003), found the findings tend to prove the hypothesis that the factors leading to positive attitude an those leading to negative attitudes are different. University of Eldoret has not been spared in the struggle of retaining employees. According to Kehr (2004), the implicit retention factors is spontaneous, expressive and pleasurable behavior and can be divided into three variables; power, achievement and affiliation. In this case power refers to dominance and social control and achievement on the other hand is when personal standards of excellence are to be met or exceeded. 
Consequently affiliation refers to social relationships which are established and intensified. Implicit and explicit retention factors relate to different aspects of the person, though both are important determinants of behavior.

The Kenyan education sector has become so competitive following the aggressive entry of both private and public universities. The institutions which were chattered by President Mwai Kibaki have made the sector to be very competitive as the schools are working to accommodate the current students' number. These calls for availability of staff in all sectors ranging from finance to casuals who help ensure the institutions dream is possible. Moreover the few qualified employees have kept on moving from one institution to another in search of better employment terms and greener pastures. As such, human capital has turned out to be an important competitive tool in the education sector which calls for proper management practices for these resources to ensure sustained competitive advantage.

The employees help create an organizational culture. In Kenya services offered by different Universities is more less the same which makes it difficult to compete on products basis. For University of Eldoret to remain competitive, they need to create an organization culture where students and parents are always satisfied with the consistent quality services offered. For the University to offer consistent services, it is important that they recruit, train, develop and retain qualified personnel.

On the other hand the costs of employee turnover can be very high. They include separation costs for example administrative time, recruitment and placement costs, training costs for the new employee, and leave alone the lost knowledge and potentially damaged customer relationships, which can result from regular employee turnover (Abbasi, \& Hollman, 2000) A multitude of factors explain why employees remain or leave an organization, but expressed intentions to stay has consistently been recognized as a reliable precursor to actual turnover and is reflective of employee commitment to the organization (Maertz \& Campion, 1998; Griffeth, Hom, \&Gaertner, 2000; Hom \& Griffeth, 1995; Hom \& Kinicki, 2001). A good match between employee and organizational values is related to employee attraction, satisfaction, and turnover.

In addition, job satisfaction has a consistent and positive association to expressed intentions to stay and to employee perceived congruence with organizational valuesAryee, Luk, \& Stone, 1998; Mitchell, Holtom, Lee, Sablynski, \&Erez, 2001; Samantrai,1992; Spector, 1997). Job satisfaction can be investigated as either an overall attitude toward the work experience or as multiple components. The components of job satisfaction include attitudes toward compensation, coworkers, and one's roles and tasks.For example, in the leisure-service profession, Yen and McKinney (2001) found job satisfaction among public park and recreation managers was positively related to perceived job characteristics such as satisfaction $\mathrm{n}$ with compensation, benefits, raise satisfaction, and pay structure (Abbasi, \&Hollman, 2000) investigated social workers and found that poor relationships with the direct supervisor and inflexibility in their current job distinguished those who stayed from those who left. Aryee, Luk, and Stone (1998) investigated factors to explain retention among employed parents and found that employee's satisfaction with their direct supervisor was related to the expressed intentions to remain with the organization.

\subsubsection{Employee Retention}

According to Zineldin (2000) employee retention is the all-round module of an organization's human resource strategies, which commences with the recruitment of the right people with the right skills that is required by the organization and continues with practices which promotes employee engagement and commitment to the organization According to Fitzenz (1990), retention is driven by several keyfactors, which ought to be managed congruently: organizational culture, strategy, pay andbenefits philosophy, and career development systems. As Day (2000) argued, ifcompanies cannot retain their employees, the economic results could be devastating foran organization. A substantial amount of value could potentially end up employed by a competitor, or become the competition.

For organizations, the high cost of recruitment and selection (Pfeffer, 1998), the lag and productivity loss during the assimilation period (Davies, 2001), the likely loss of business opportunity poor customer relationship (Clarke, 2001, Messmer, 2000), and hidden cost of loss productivity (Das, 2002) have subsequently highlighted the importance of retaining committed employees as an aspect of survival for organizations. Employers seek to treat employees as valued assets who can be a source of competitive advantage through their commitment, trust, adaptability and high quality skills and knowledge (Storey, 1992). This empowerment should increase the competitiveness of the business. Arthur (1994) concluded that by using commitment strategies, organizations had significantly higher performance and lower turnover, compared to those using control strategies. Thus, to gain employees' career commitment to the organization and increase retention the employer needs to identify which retention factors more influence to career commitment. Outstanding employees may leave an organization because they become dissatisfied, underpaid, unmotivated, the company not provide training and not give opportunity to get promotion (Coff, 1996), and while trying to retain employees within the organization they may present other challenges as well. They may demand higher wages, 
not comply with organization practices, and not interact well with their coworkers or comply with their supervisor directions.

\subsection{Statement of the Problem}

Human resource management play pivotal role in employees retention. These roles include practices such as compensation \& rewards, job security, training \& developments, supervisor support culture, work environment and organization justice (Muigai, 2008). According to Cole,(2000) in a study on high performance he found out that employee satisfaction and retention are considered the cornerstone for success of organization. Moreover several studies have been done on the subject of employee retention among organizations. Mungai (2008) noted that a number of organizations do not consider the impact of employee retention as a strategy in managing competition and are likely to become victims of industry competition.

According to Cappelli (2000) employees are among the foremost essential determinants and leading factors that ensure retention. An employee who is contented with his job would perform his duties well and be committed to the job. Thus, it's of utmost importance for employers to understand the factors affecting employee retention. However, Observations indicated that University of Eldoret is facing challenges such as, poor career development, limited growth opportunities and poor compensation strategies for its employee that can be attributed to political interference, this has undermined effective and efficient service delivery; a pointer to employee commitment and retention.

In Kenya few studies have been done on employee retention; Njoroge (2007) did a survey of factors that influence employee retention in manufacturing firms in Nairobi and established that employee retention in the manufacturing industry was influenced by the reward, working environment, career development opportunities and employee motivation. By knowing the effect of employee retention as a strategic response to the competitive business environment, it enables an organization to strategize on how to meet the objectives of the organization because employees are an important resource in an organization.

Lepilale (2009) did a study on the relationship between employee retention management practices and voluntary labour turnover in five star hotels in Nairobi and found out that employee retention management practices employed by the hotels had great impact on the employee turnover rates in those hotels. Based on all this arguments the University of Eldoret need to provide employee focused, good employment, high involvement practices that build a positive workplace experience to attract and retain employees, hence this study seeks to provide organization specific literature considering the fact that every organization is unique in its own way. This study therefore sought to fill this research gap by examining factors affecting employee retention at University of Eldoret, Kenya.

\subsection{Employee Retention}

\section{II. literature review}

Employee retention issues are emerging as the most critical workforce management challenges of the immediate future. Since the mid-1990s, scholarly research investigations have been focusing not only on determining why employees leave organizations but also concentrating on those factors positively influencing employees to stay (Hoisch, 2001), as well as the benefits associated with retaining tenured workers (Ramlall, 2004). Effectively designed and well implemented employee retention programs that increase employee tenure more than pay for themselves through reduced turnover costs leads to increased productivity (Simons and Hinkin, 2001).

Fostering employee commitment can have a great impact on decreasing turnover rates. Bishop (1997) found that commitment has a positive effect on productivity, turnover and employees willingness to help coworkers because increased employee commitment improves team performance and productivity and decrease absenteeism, turnover, and intention to quit by employees. However, companies can take action to ensure that these increasing trends are minimized within their own individual organizational cultures. Therefore, strong retention strategy must be implemented in an organization if the organization is to promote employee retention.

Byrnes (2002) notes that there are five essential steps for a company to develop an effective retention strategy: a corporate values system must be defined based upon the organization's values and vision where the values guide the company and identify those employees desiring to move in the same direction; trust must be established within all parts of the business because security comes from trust and trust comes from honesty and communication; assess employee priorities through surveying from time to time to allowing organization to structure effective reward programs, thus increasing employees satisfaction; fourth, Byrnes recommends doing industry homework to enables companies understand competitors compensation and benefit programs so that organizations can keep pace with the industry remuneration packages. A clearer understanding of what is expected by employees within the industry provides the company the opportunity to increase satisfaction. Finally, the creation of a compensation and benefit package, supportive of company values and employee needs, is essential. 
Retention factors are utilized as an important topic for managers, organizations, and organizational researchers (Abbasi and Hollman, 2000; Arkin, 1997; Muchinsky, 1997; Sightler and Adams, 1999). Consistently, retention of talented employees can be a source of advantage for an organization. But there are challenges in attempting to retain these employees (Barney, 1991; Wernerfelt, 1984; Pettman, 1975). Meanwhile, from their view of these retention factors from 1995 to 2004, were used to identify the critical factors in high technology employees' retention (McNee, 1998; Dockel, 2004).

Compensation, job characteristics, training and development opportunities, supervisor support, and promotion were identified as the top five retention factors. This was specifically chosen because the demand for high technology employees skyrocketed, turnover increased, job hopping became the norm and the shortage of qualified candidates existed. Companies try to keep these valuable employees with their cutting edge knowledge and skills, but the demand for high technology employees with skills has increased substantially, e.g. for ten positions only eight candidates with the required skills qualify (McNee, 1998; Murphy, 2000). To add to this, competitors use aggressive recruitment tactics to try and woo away these valuable employees. Because of this shortage, it has become critical to retain high technology company most valuable technical employees.

On the other hand, Dockel (2004) has identified top five of retention factors including compensation, job characteristic (skill variety and job autonomy), training and development, supervisor support and promotion. Overall, the justification to select five factors widely utilized by most companies to motivate their employees, it seems reasonable to identify them as a means of examining the effect on career commitment (Turbin and Rosse, 2006).

\subsection{Compensation}

Rewards are any objects stimuli or events that increase the probability and intensity of behavioral actions leading to a such objects (learning, also called positive reinforcement),generate approach and consummatory behavior and constitute outcomes of economic decision-making, and induce subjective feelings of pleasure and hedonic. Rewards are of crucial importance for individual and support such elementary processes as drinking, eating and reproduction. Largely similar behavioral processes are engaged for higher order rewards such as money, novelty and cognitive and social rewards. The basic reward objects are polysensory and do not engage specialized reward receptors, and the brain extracts the reward information from visual, auditory, somato sensory, olfactory and other sensory information. The identification of higher order rewards depends on additional cognitive processes. Thus rewards are not defined by the physics and chemistry of their inputs but by the behavioral reactions they induce (Schultz, 2007).

Furthermore, primarily rewards include cash compensation, benefits, and other non cashforms and the work experience. Strategic reward plans go beyond cash to include training and educational opportunities, job redesign, flexible work schedules, stock options and recognition awards such as merchandise and travel. Non cash rewards, such as on-siteday care, fitness centers, dry-cleaning services and automatic teller machines, add convenience to employees' daily lives and engender higher loyalty (Deci, 1971). Work at- home and job-sharing arrangements enable employees to better balance work and family responsibilities and afford employers the necessary flexibility to respond tobusiness needs. The total reward system is defined here to include base salary, variable pay, direct compensation, perquisites, benefits, performance management, training, career development, coaching and other employee-related policies. Combinations of variable pay, recognition and celebration and benefits are essential to providing a total reward package (Milne, 2007).

Currently, many organizations are implementing or planning to implement, reward and or recognition programs believing that these will help bring about the desired cultural change (Milne, 2007). In some organizations, large amounts of money are being invested in these types of activities and some managers are required specifically to set aside ascertain amount from their budgets for this purpose. This rationale is based on the assumption that these types of incentives will encourage employee loyalty, foster teamwork and ultimately facilitate the development of the desired culture that encourages and supports knowledge sharing (Deci, 1971). According to Kanter (1987), many organizations rewards are differentiated on the basis of status (rather than contribution)and, often, the only way an individual can increase his or her pay is to get promoted. This usually motivates them to "look out for themselves" rather than improve their overall contribution. Meanwhile, money is still the primary incentive used to lure information technology professionals. However, most experts agree that money is not the long term answer for hiring, and especially for keeping, skilled high technology employees (Leinfuss, 1998).According to Higginbotham (1997) high salaries are not essential, but "good" and "fair" salaries showed a strong correlation with intention to stay, indicating that as long as the compensation is competitive, financial rewards are not the primary factor in retention; Kochanski and Ledford (2001) support this statement, which indicated that the actual level of pay is less important than feelings about pay raises and the process used to administer them. Employees want to understand how the pay system works, and want to know how they can earn pay increases. Once the pay level has been reached other things become important, the intangibles, e.g. career, supervisor support, work and family balance (Tomlinson, 2002).Employee benefits and 
benefits in kind (fringe benefits, perquisites, and perks) are various non-wage compensations provided to employees in addition to their normal wages or salaries (Farris, 2000). Where an employee exchanges (cash) wages for some other form of benefit, this is generally referred to as a 'salary sacrifice' arrangement. In most countries, most kinds of employee benefits are taxable to at least some degree. For example: housing, group insurance (health, dental, and life), disability income protection, retirement benefit.

Relatively, the purpose of the benefits is to increase the economic security of employees. The term perks or perks is often used colloquially to refer to those benefits of a more discretionary nature (Farris, 2000). Often, perks are given to employees who are doing notably well and/or have seniority. Common perks are company cars, hotel stays, free refreshments, leisure activities on work time (golf, etc.), stationery, allowances for lunch, and when multiple choices exist first choice of such things as job assignments and vacation scheduling. They may also be given first chance at job promotions when vacancies exist.

Furthermore, Pfeffer (1998) argued that rewards system such as a higher salary base, gain sharing, bonuses and employee stock options, act as incentives for employees to be committed and motivated to achieve organizational goals. In a study of 250 employees of a manufacturing operation, Oliver (1990) found a positive correlation ( $r=.56, \mathrm{p}>.01)$ between work rewards and commitment. Buchko (1993) suggest that benefit practices can be associated with turnover. He found that in organization in which benefits were a higher percentage of total labor costs and those organizations whose benefits packages were described to be of higher quality, tended to report lower rates of employee attrition.

Buchko suggests that this may be because employees are satisfied with the benefits they received or might be because the rewards and benefits received are binding investments that would induce career commitment. These results imply that size and types of benefits provided for by organization play a significant role in reducing employee turnover.

$\mathrm{H}_{\mathrm{O} 1}$. There is no significant relationship between compensation and employee retention at University of Eldoret.

\section{Materials And Methods}

This study adopted a descriptive study design. The population for this study was 1500 respondents drawn from different levels of management at University of Eldoret. The study used 5-point likert questionnaires as data collection instruments. The Cronbach's coefficient alpha was applied on the results obtained to determine how items correlate in the same instrument. Cronbach's coefficient Alpha of more than 0.7 was taken as the cut off value for being acceptable which enhanced the identification of the dispensable variables and deleted variables. Data was analyzed by use of Descriptive statistics (frequencies, percentages, means and standard deviation )was used to analyse data and inferential statistic chi-square $\left(\mathrm{x}^{2}\right)$ was also used to analyze the interdependency of variables, which may not otherwise be obvious

\subsection{Chi-Square Analysis of Compensation}

\section{Results And Discussion}

The chi square results on compensation and employee retention at University of Eldoret, Kenya are shown in table 4.1 below

\begin{tabular}{|l|l|l|l|}
\hline \multicolumn{5}{|l|}{ Table 4.1 Chi-Square Analysis of Compensation } \\
\hline Variable & Compensation \\
\hline & Observed F & Expected F & Chi-square values \\
\hline Highly competitive wage system & 43 & 46.8 & 0.309 \\
\hline $\begin{array}{l}\text { Compensation satisfaction among } \\
\text { employees }\end{array}$ & 68 & 46.8 & 9.603 \\
\hline $\begin{array}{l}\text { Communicated policies and its } \\
\text { compensation policies }\end{array}$ & 37 & 46.8 & 2.052 \\
\hline $\begin{array}{l}\text { Human resource practices understanding of their } \\
\text { Clearectives and use compensation }\end{array}$ & 42 & 46.8 & 0.167 \\
\hline Total & $\mathbf{2 3 4}$ & $\mathbf{2 3 4}$ & 0.492 \\
\hline
\end{tabular}

From the findings on table 4.1 above, the calculated chi square value of Highly competitive wage system was (0.309), Compensation satisfaction among employees (9.603), Communicated policies and its compensation policies (2.052), Human resource practices (0.167), and Clear understanding of their objectives and use compensation (0.492).The overall chi-square value for compensation was (12.623) at 5\% level of significance. The Chi-square tests for compensation was significantly above the critical values determined at different degrees of freedom. Hence, the study confirms that compensation is factor in that ensures employee commitment in organizations. These results indicate that compensation is likely to enhance employee retention because there was no significant difference between observed and expected frequencies. These findings are 
similar to previous research findings by Pfeffer (1998) argued that rewards system such as a higher salary base, gain sharing, bonuses and employee stock options, act as incentives for employees to be committed and motivated to achieve organizational goals

\section{Conclusion}

The study concluded that through compensation strategies, it was concluded that; there is a highly competitive wage system that promotes employee commitment and thus results in the attraction and retention of a superior workforce, there is compensation satisfaction among employees that play a role in role in employee retention, Well communicated policies and its compensation policies are set in the university, human resource practices is key in employee retention without any pay-based retention incentives and the university has a clear understanding of their objectives and use compensation as a tool for influencing employee behavior. These findings are supported by Maslow's Hierarchy of Needs which is based on the assumption that people are motivated by a series of five universal needs. These needs are ranked, according to the order in which they influence human behavior, in hierarchical fashion. This theory determines the extent to which employee retention for better services, organizational output and quality service delivery. It outlines the various levels of needs and thus motivated by a series of five universal needs that ensures productivity and continued employment.

\subsection{Recommendation of the Study}

Based on the findings of this study, the following recommendations were made:

i. University of Eldoret should ensure that the policy governing the level of compensation should be improved to enhance a higher rate of employee retention; there is a general need to maintain the organizational strategies as the research revealed that they are the highest predictor of employee retention

ii. The study also recommends that training is sign of organization commitment to employees. Training also reflects organization strategy that is based on value adding rather than cost lowering. Therefore university of Eldoret should ensure availability of comprehensive range of training, skill and career development which is a key factor of employee attraction and retention

iii. A training program should be established as a regular practice for provision of training and retraining especially refreshment courses opportunities for their employees. This would not only satisfy employees' growth need but also enhance employee retention.

iv. University of Eldoret should create effective promotion opportunities within organization and provides training opportunities and skill development to improve their employee's. Also University of Eldoret should desire to strengthen their bond with employees must spend on the development of employees to ensure employee satisfaction.

\section{.2 Suggestion for Further Research}

This study established the factors affecting employee retention at University of Eldoret. Therefore, there is a need for further research geared toward establishing the factors affecting employee retention in other industries like banking sector, manufacturing industries, as well as other educational institutions so that the area of study is equipped with more information and allow for generalization of results.

\section{References}

[1]. Abbasi, S. M., \&Hollman, K. W. (2000), Turnover: The real bottom line. Public Personnel Management, 333-343.

[2]. Agarwal, R., \&Ferratt, T. W. (1999), coping with labour scarcity in IT: Strategies

[3]. Amabile, T. M. (1993), Motivational synergy: Toward new conceptualizations of intrinsic and extrinsic motivation in the workplace. Human Resource Management Review, 3, 185-201.

[4]. Armstrong, M. (2007), Employee Reward Management and Practice, London and Philadelphia: Kogan Page.

[5]. Arthur, J. B. (2004), Effects of human resources systems on manufacturing performance and turnover. Academy of Management Journal, 670-687.

[6]. Ayree, S., \&Chay, Y.W. (1994), An examination of the impact of career-oriented mentoring on work commitment attitudes and career satisfaction among professional and managerial employees, British Journal of Management.

[7]. Bailyn, L., \& Lynch J. (1983), Engineering as a life-long career: its meaning, its satisfaction and its difficulties. Journal of Occupational Behavior, 263-283.

[8]. Baker, K. \& Gandhi, D. (1993). The Perception of Dividends by Canadian Managers: New Survey evidence', International Journal of Managerial Finance.

[9]. Barney, J.B. (1991), Firm Resources and Sustained Competitive Advantage, Journal of Management, 99- 120.Buckingham: Open University Press. pp: 22-31.

[10]. Cole, C. L. (2000). Building loyalty in Workforce, $42-47$.

[11]. Cappelli, P. (2001), A market-driven approach to retaining talent, Harvard Business Review on Finding and Keeping the Best People, Harvard Business School Press, Boston, MA, pp.27-50

[12]. Clarke, K.F. (2001). 'What businesses are doing to attract and retain employee becoming an employer of choice.' Employee Benefits Journal, March, pp. 34-37.

[13]. Cougar J. D. \&Zawacki R. A. (1980), Motivating and managing computer personnel. New York: Wiley. 
[14]. Das, H. (2002), The four faces of pay: An investigation into how Canadian managers view pay, International Journal of Commerce \& Management, 12, 18-41.

[15]. Davies, R. (2001). How to boost staff retention, People Management,

[16]. Day, D.V. (2000), Leadership development: A review in context, Leadership Quarterly, 581-613.

[17]. Eisenberger, R., Fasolo, P., \& Davis-LaMastro, V. (1990), Perceived organizational support and employee diligence, commitment, and innovation. Journal of Applied Psychology.

[18]. Farris, G. R. (1987), The validity of the job characteristic model: A review and meta-analyses. Personnel Psychology, 4 (2), 287322.

[19]. Fitz-enz, J. (1990).Getting and keeping good employees.In personnel, 25-29.

[20]. Fraenkel, J., \&Wallen, N. E. (2000) How to design and evaluate research in education(4th ed.). Boston: McGraw-Hill.

[21]. Griffeth, R. and Hom, P (2001) Retaining valued employees. Thousand oaks, calif: sage publications

[22]. Higginbotham, J. S. (1997), The satisfaction equation. Research \& Development, (10),1-9.

[23]. Hytter, A. (2007). Retention strategies in France and Sweden. The Irish Journal of Management, 59-79.

[24]. Kehr, H. M. (2004). Integrating implicit motives, explicit motives, and perceived abilities. The compensatory model of work motivation and volition. Academy of management review.

[25]. Maertz, C.P., Jr., \& Campion, M.A. (1998). 25 years of voluntary turnover research: A review and critique. International Review of Industrial and Organizational Psychology, 49- 81.Targeted Employee Retention.

[26]. Marsh, R. M., \&Mannari, H. (1977), Organizational commitment and turnover: a predictive study. Administrative Science Quarterly, 57-75.Marx E. (2006), The influence of task and role characteristics on organizational commitment. Unpublished dissertation M.Com.(Human Resources Management).University of Pretoria.

[27]. Mugai, E.W (2008), Innovation Strategies adopted by Equity Bank. Unpublished MBA Research Project of the University of Nairobi. Nairobi, Kenya.

[28]. Njoroge S. W. (2007), A survey of factors that influence employee retention in manufacturing firms in Nairobi. Unpublished MBA project.University of Nairobi.

[29]. Pfeffer, J. (1998), Seven practices of successful organizations, California Management Review, Vol. 40, 2012.

[30]. Pleffer A. (2007). Work-Life Balance: The Number 1 Retention Factor. Retrieved Schultz, W. (2007), Reward. Scholarpedia, 1652

[31]. Storey J and Sisson K (1993). Managing Human Resources and industrial Relations, Tomlinson, A. (2002). High Technology workers want Respect. Survey Canadian Human Resources Reporter, vol. 15, issue 3, and p.2.

[32]. Walker J.W. (2001), Human Resource Planning, Vol. 24 No. 1, pp. 68

[33]. Zineldin, M. (2000), TRM Total Relationship Management, Student litterateur, Lund 